\title{
Water Level Control Sistem Otomatis Sederhana pada Tandon Air di Kawasan Perumahan
}

\author{
Afgan Suffan Aviv $*^{1)}$, Ari Wardayanti ${ }^{2)}$, Endah Budiningsih ${ }^{3)}$, Afni Kurnia Fimani ${ }^{4)}$, \\ Bambang Suhardi ${ }^{5)}$ \\ ${ }^{1,2,3,5)}$ Program Studi Teknik Industri, Fakultas Teknik, Universitas Sebelas Maret, Jalan Ir. \\ Sutami No. 36A, Surakarta, 57126, Indonesia \\ 4) Program Studi Agroteknologi, Universitas Sebelas Maret, Jalan Ir. Sutami No. 36A, \\ Surakarta, 57126, Indonesia
}

\begin{abstract}
Plenty of water and electricity are wasted in residential areas because people often forget turning off the water pump or do not know when the water tank is full. Solution of these problems is using a water level control as an automatic tool to turn off and turn on the water pump. However, the water level control that exist today has many shortcomings. It has a complicated operating system, especially for people in a residential area with a range of price more than IDR 50,000. So this study was conducted with the aim of simplifying the system of water level control so its price is more affordable and simple operation, knowing the working principle and study the effectiveness and efficiency. From the research that has been done resulting an automatic water level control with more simple system and a production cost of IDR 19,000 with a selling price of IDR 25.000.
\end{abstract}

Keywords: water level control, automatic, water tank, residential area

\section{Pendahuluan}

Air mempunyai peranan penting dalam kelangsungan makhluk hidup di bumi. Air akan sangat bermanfaat bagi kehidupan di bumi dalam jumlah yang proporsional( Arifin, 2015).Krisis air bersih menjadi masalah yang serius di Indonesia. Sindo (2016) menyatakan krisis air bersih mulai dirasakan sebagian warga Kabupaten Jepara memasuki musim kemarau tahun ini karena jarannya hujan. Rio Kuswandi dalam Kompas.com (2015) menyatakan juga sejak sebulan terakhir ini Kota Bandung, Jawa Barat, mengalami krisis air bersih karena PDAM jarang mengalir di rumahnya. Solopos.com (2016) dari Sekretariat Jenderal IAHLI menyatakan pada tahun 2015 cadangan air tanah bebas (dangkal) saat musim pancaroba di Solo tersisa 1,338 juta $\mathrm{m}^{3}$. Sedangkan jumlah air tanah tertekan dalam) saat yang sama mencapai 21 juta $\mathrm{m}^{3}$.Sementara kebutuhan air penduduk Solo_(menurut riset terakhir BPS mencapai 510.077 jiwa) sebesar 51 juta liter/hari atau 18,615 miliar liter/tahun. Gangguan air bersih bisa terjadi karena beberapa hal, yaitu hal-hal yang terencana seperti pemeliharaan instalasi pengolahan air bersih dan perbaikan pipa distribusi( Ilfan Arifin,2015).

Masalah krisis air bersih juga ditambahi dengan masalah pemborosan energi dan sumber daya terjadi pada pengisian penampung air pada kawasan perumahan (Adini, 2012). Haryanto (2007) menyatakan bahwa banyak air dan listrik yang terbuang sia-sia karena lupa mematikan pompa air ataupun tidak tahu kapan tandon air tersebut penuh maka diperlukan sistem otomatisasi sederhana dalam segi proses maupun peralatan dalam proses pengisian air dalam tangki penampungan. Pompa air yang baik adalah pompa air yang ditunjang dengan suatu alat yang dapat mengontrol ketinggian level air pada bak penampungan atau tangki. Dengan adanya pengontrol ketinggian level air pada tangki maka, penggunaan air yang berlebih bisa diatasi (Andani dkk., 2011). Masalah yang muncul ketika level ketinggian air dalam tandon penampung air tidak diketahui, dimungkinkan bisa terjadi keadaan tandon yang meluap atau kosong

\footnotetext{
*Correspondance: afgansuffan@gmail.com
} 
dikarenakan kurangnya pengontrolan terhadap tandon tersebut, sehingga perlu dibuat suatu alat yang dapat melakukan pengontrolan tandon secara otomatis (Arifin, 2015).

Water Level Control adalah satu dari sekian banyak sistem yang ada dalam dunia industri. Dengan sistem ini, pemilik rumah tidak perlu khawatir dalam pengisian tandon air dirumah. Ketika sistem ini diaktifkan, pemilik rumah tidak perlu menunggu apakah tangki air sudah penuh atau belum. Dengan demikian pemilik rumah dapat menghemat air, listrik dan waktu, karena tidak ada air dan listrik yang terbuang sia-sia, karena lupa mematikan pompa air (Hariyanto dkk., 2010).

Namun Water Level Control yang ada saat ini memilki sistem yang rumit dengan kisaran harga lebih dari Rp 50.000,00. Ada dua macam alat yang biasa di gunakan oleh masyarakat umum saat ini, yang pertama dengan sistem sensor tekanan air. Pada saat air hampir habis, tekanan air menjadi kecil maka sensor akan bekerja dan pompa air akan menyala dan mati secara otomatis saat tangki air sudah penuh. Alat dengan penggunaan sensor tekanan adalah Water Level Control. Water Level Control yang ada dipasaran saat ini menggunakan teknologi berbasis mikrokontroler (Nahkoda dkk., 2009). Kelemahan mikrokontroler adalah harga yang tidak terjangkau dan pengoperasian yang sulit bagi masyarakat umum. Sehingga alat Water Level Control berbasis mikrokontroler sulit diterima jika dipasarkan kepada masyarakat umum dan industri rumahan. Kedua, alat pompa air otomatis adalah dengan sistem pelampung. Kelemahannya adalah pemasangan yang sulit dan keakuratannya yang masih kurang, meskipun harganya lebih murah. Maka diperlukan alat yang lebih sederhana dan lebih ekonomis untuk dijangkau semua kalangan masyarakat. Di samping sederhana, sistem yang dibuat juga diharapkan untuk dapat digunakan dalam dunia industri dan kawasan perumahan.

Maka penelitian ini dilakukaan dengan tujuan menyederhanakan pembuatan Water Level Control sehingga harga jualnya lebih terjangkau dengan sistem yang lebih sederhana, mengetahui prinsip kerja Water Level Control dengan bahan yang sederhana dan murah dalam menghemat air dan energi listrik serta mengetahui serta mempelajari efektifitas dan efisiensi Water Level Control otomatis sederhana dalam penggunaan di kawasan perumahan.

\section{Metode Penelitian}

Metode yang digunakan dalam penelitian ini digambarkan pada gambar 1 dibawah ini, yaitu dengan melakukan studi literatur, pencarian alat dan bahan, pembuatan dan perancangan Water Level Control sistem otomatis sederhana, pengujian alat dan penyempurnaan serta packaging.

Penelitian dimulai dengan melakukan studi literatur yaitu dengan mencari dan mengkaji informasi yang relevan terkait dengan Water Level Control dengan sistem otomatis sederhana.

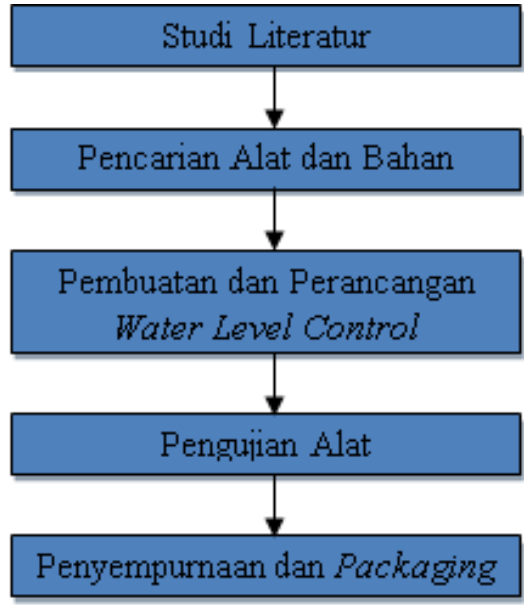

Gambar 1. Metode Penelitian 
Kemudian melakukan pencarian alat dan bahan. Alat dan bahan yang digunakan adalah barang-barang yang mudah ditemukan dan dicari di lingkungan sekitar oleh masyarakat umum dengan tujuan apabila alat ini mengalami kerusakan maka dapat diperbaiki secara mandiri oleh masyarakat umum. Pembuatan alat ini terdiri perancangan alat pendukung yang terdiri dari : (1) pompa air sebagai pemompa air dari sumur, (2) penampung air (tandon) sebagai tempat menampung air, (3) pipa paralon sebagai penyalur air, (4) kran air untuk membuang air dari tandon air dan (4) Water Level Control yang terdiri dari kabel listrik, botol plastic $30 \mathrm{ml}$ dan $100 \mathrm{ml}$, benang, kran air, dudukan lampu, saklar, magnet,dan lainnya. Alat dan bahan yang didapatkan kemudian dibuat sesuai dengan rancangan yang telah dibuat. Hasil rancangan alat digambarkan pada gambar 2 .

Alat yang sudah dibuat kemudian dilakukan pengujian untuk mengetahui adakah kekurangan atau ketidaksempurnaan alat. Melalui pengujian alat ini juga dapat diketaui apakah alat yang dibuat sudah cukup efektif dan efisien. Dari hasil perancangan alat Water Level Control diketahui bahwa alat tersebut dapat berpotensi untuk dipatenkan.

Setelah melakukan pengujian alat dilakukan penyempurnaan alat dengan pengujian terakhir kali. Packaging pada alat Water Level Control digunakan dengan menggunakan kemasan berupa kardus yang didalamnya berisi alat Water Level Control tersebut. Desain logo atau merk serta pembuatan desain kemasan dibuat untuk memudahkan konsumen mengingat alat tersebut, menarik minat konsumen untuk membeli dan menggunakan alat Water Level Control serta meningkatkan potensi terjadinya kerjasama dengan industri terkait sehingga alat Water Level Control dapat diproduksi massal dan diterima masyarakat luas.

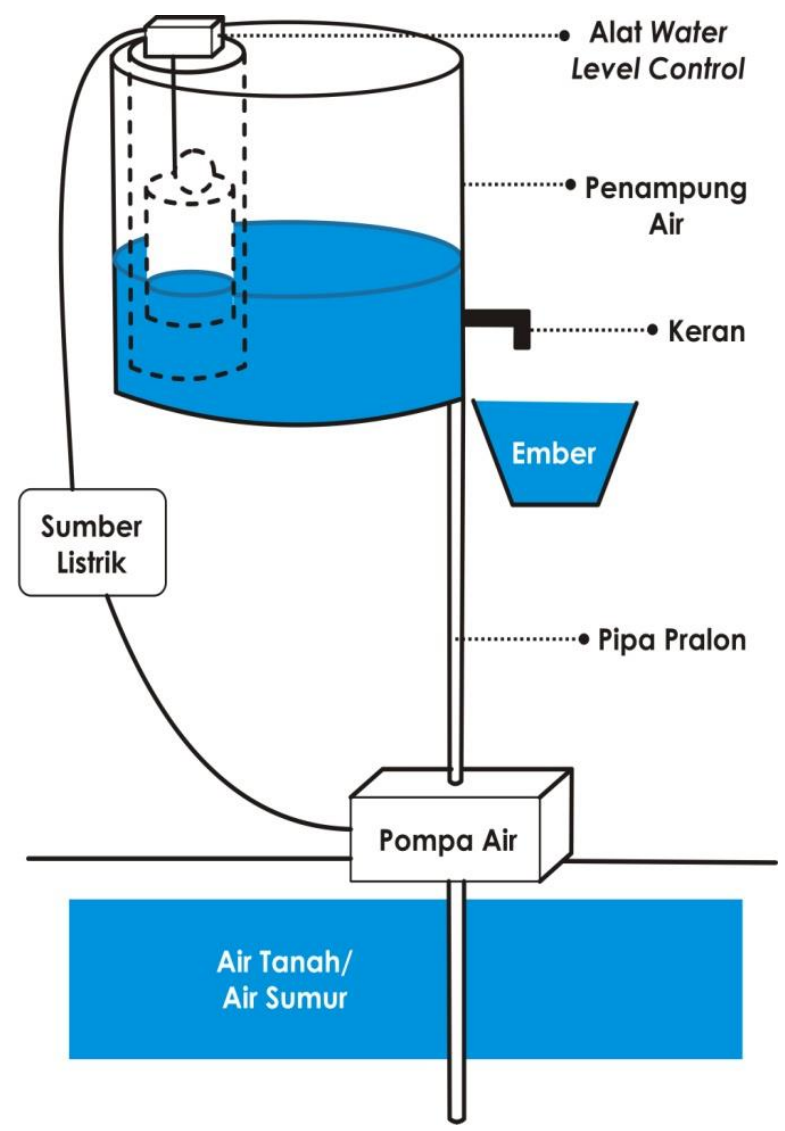

Gambar 2. Rancangan Alat Water Level Control pada Pemompa Air 


\section{Hasil dan Pembahasan}

Dari penelitian yang telah dilakukan dihasilkan Water Level Control sederhana dengan alat dan bahan yang digunakan seperti pada tabel 1 dan tabel 2 .

Tabel 1. Alat dan Bahan Pemompa Air

\begin{tabular}{ll}
\hline No & Bahan dan Alat \\
\hline 1 & Pompa Air \\
2 & Kabel Listrik \\
3 & Saklar \\
4 & Pipa Paralon \\
5 & Tandon Air \\
6 & Pipa Kran \\
7 & Kran \\
\hline
\end{tabular}

Dari tabel 1 dijelaskan bahwa perancangan pemompa air terdiri dari beberapa alat yang dirangkai sesuai dengan desain rancangan pada gambar 2. Perancangan pemompa air ini digunakan dalam pengujian Water Level Control sistem otomatis sederhana untuk menguji apakah alat dan bahan yang telah ditentukan dapat menghasilkan alat Water Level Control yang berfungsi dengan baik.

Tabel 2. Alat dan Bahan Water Level Control

\begin{aligned} & \hline No Bahan dan Alat \\ & \hline 1 Dudukan Lampu \\ & 2 Pegas \\ & 3 Magnet \\ & 4 Botol Plastik \\ & 5 Benang \\ & 6 Kabel Listrik \\ & 7 Spet/tabung \\ & 8 Konduktor-Isolator \\ & \hline\end{aligned}

Pada perancangan Water Level Control diperlukan alat dan bahan seperti pada tabel 2 yang kemudian dirangkai sesuai desain rancangan Water Level Control otomatis sederhana pada gambar 3. Pemilihan alat dan bahan tersebut dilakukan beberapa kali percobaan hingga didapatkan alat dan bahan yang paling tepat digunakan sebagai Water Level Control sistem otomatis sederhana.

Dalam perancangan alat Water Level Control sistem otomatis sederhana ini digunakan 2 buah dudukan lampu yang berfungsi sebagai pusat penghubung dan pemutus aliran listrik pompa air, dudukan lampu dipilih sebagai komponen alat ini karena daya tahan terhadap panas yang dihasilkan oleh arus listrik cukup baik mengingat fungsi dudukan lampu sesungguhnya sehingga alat ini akan memiliki umur yang cukup lama. Di dalam dudukan lampu tersebut terdapat konduktor, isolator dan pegas. Konduktor berfungsi untuk menghubungkan arus listrik, isolator berfungsi untuk memutuskan arus listrik sedangkan pegas yang melingkupi batang konduktorisolator berfungsi agar pergerakan batang konduktor-isolator tersebut cukup elastis ketika naik dan turun didalam dudukan lampu. Magnet diletakkan didalam botol plastik berisi udara, ketika botol berisi udara ini naik dan menyentuh dudukan lampu magnet ini akan menahan botol plastik agar tetap pada posisinya karena dibawah dudukan lampu tersebut terdapat ring baut sehingga botol plastik ini dapat menahan batang konduktor-isolator dengan posisi bagian isolator memutus arus listrik. Benang berfungsi untuk menghubungkan botol plastik berisi udara dengan botol 
plastik berisi air $100 \mathrm{ml}$. Dalam penelitian ini belum dilakukan pengujian resistansi benang yang digunakan terhadap air untuk mengetahui berapa lama benang tersebut dapat digunakan dalam alat Water Level Control sistem otomatis sederhana. Kemudian botol plastik berisi air $100 \mathrm{ml}$ berfungsi sebagai pemberat sehingga ketika air dalam tandon hampir kosong botol ini akan menarik botol berisi udara yang semula menahan batang konduktor-isolator pada posisi memutus arus listrik, karena botol plastik berisi udara tersebut tertarik ke bawah maka batang konduktorisolator pada bagian konduktor berada pada posisi menghubungkan arus listrik.

Prinsip kerja dari alat Water Level Control sistem otomatis sederhana dengan mengisi penampung air atau tandon hingga penuh secara manual, membuang air melalui kran yang telah disiapkan hingga habis, jika air didalam tandon mulai berkurang, maka botol plastik $100 \mathrm{ml}$ yang berisi air akan turun kebawah dan tali yang terhubung antara botol $30 \mathrm{ml}$ dan saklar akan saling tertarik dan mengakibatkan pengait besi tertarik dan mengubah saklar dari kondisi off menjadi on. Saat saklar dalam kondisi on, pompa air akan menyala dan air akan mengisi tandon air sampai penuh. Saat air penuh botol plastik akan bergerak ke atas sebelum air tumpah, bagian kepala botol plastik akan terangkat ke atas karena tekanan air yag terus masuk dan mengakibatkan saklar berpindah dari kondisi on menjadi off dan pompa air otomatis akan mati.

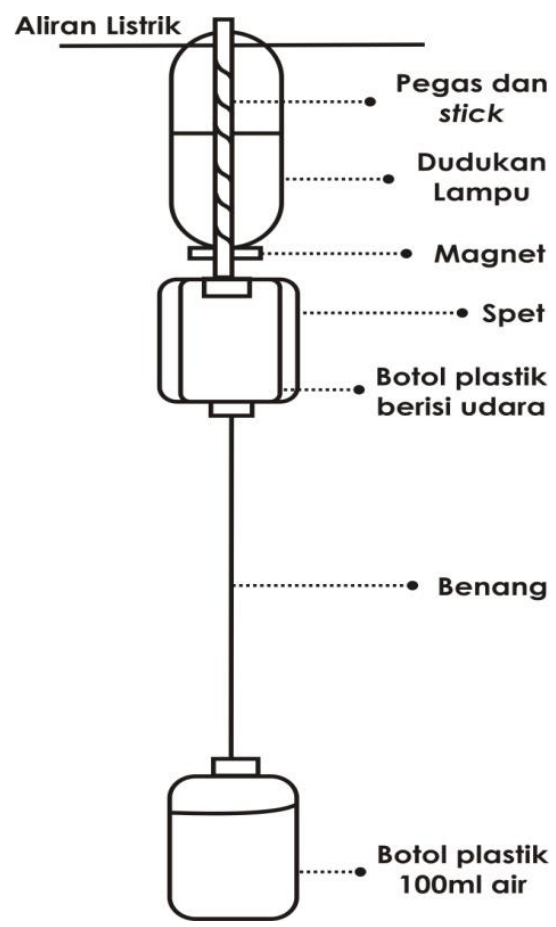

Gambar 3. Rancangan Alat Water Level Control Otomatis Sederhana

Tahap selanjutnya adalah pengujian alat, pengujian dilakukan dengan trial error dimana bahan-bahan yang telah dipilih dan dirancang menjadi alat Water Level Control dipasang pada tandon air untuk mengetahui apakah alat ini dapat mematikan pompa air saat tandon air penuh dan menghidupkan pompa air saat tandon air hampir kosong. Dari pengujian didapatkan bahwa alat dan bahan pada tabel 2 merupakan alat dan bahan yang paling tepat sebagai alat Water Level Control sistem otomatis sederhana.

Tahap berikutnya adalah tahap desain yang akan digunakan untuk kemasan dan ditempelkan pada alat Water Level Control. Setelah melakukan desain dan packaging dilakukan perhitungan biaya dan margin keuntungan yang didapat dari penjualan alat Water Level Control pada tabel 3. Pada tabel 3 dijelaskan biaya pembuatan alat Water Level Control dari awal sampai packaging. Berdasarkan hasil perhitungan didapatkan jumlah biaya produksi pembuatan alat 
Water Level Control sebesar Rp 19.000,00. Sehingga diputuskan bahwa dalam penjualan alat water level control sebesar Rp 25.000,00 dengan margin keuntungan sebesar 24\%. Namun jika alat ini diproduksi secara massal, biaya produksi dapat lebih ditekan lagi dan dapat meningkatkan margin keuntungan yang didapatkan.

Tabel 3. Biaya Produksi dan Penjualan Water Level Control

\begin{tabular}{llll}
\hline Alat dan Bahan & Harga Satuan & Jumlah & Total Harga \\
\hline Dudukan Lampu & Rp 3.000,- & 2 & Rp 6.000,- \\
Magnet dan Pegas & Rp 2.500,- & 1 & Rp 2.500,- \\
Botol Plastik & Rp 1.000,- & 2 & Rp 2.000,- \\
Benang & Rp 5.000,- & 0,1 & Rp 500,- \\
Spet & Rp 2.000,- & 1 & Rp 2.000,- \\
Lain-Lain & Rp 1.000,- & 1 & Rp 1.000,- \\
Packaging & Rp 2.000,- & 1 & $\operatorname{Rp~2.000,-~}$ \\
Biaya Tenaga Kerja & & & $\operatorname{Rp~2.000,-~}$ \\
BOP Listrik & & & Rp 1.000,- \\
Jumlah Biaya & & & $\operatorname{Rp~19.000,-~}$ \\
Harga Jual & & & Rp 25.000,- \\
Margin Keuntungan & & & $24 \%$ \\
\hline
\end{tabular}

Harga jual dari alat Water Level Control sederhana ini lebih murah dari harga Water Level Control yang sudah ada dipasaran. Sehingga alat ini dapat bersaing di pasar. Serta desain yang menarik dapat meningkatkan juga potensi pembelian dari alat Water Level Control sistem otomatis sederhana ini.

\section{Kesimpulan}

Alat Water Level Control sederhana dirancang dengan menggunakan bahan-bahan berupa dudukan lampu, pegas, magnet, botol plastik, benang, kabel listrik, keran dan saklar piano engkal. Dalam KC ini dihasilkan alat Water Level Control sederhana dengan biaya sebesar Rp 19.000,- sehingga didapatkan harga jual yang lebih terjangkau yaitu sebesar $\mathrm{Rp} 25.000,00$. Prinsip kerja dari alat Water Level Control sistem otomatis sederhana ini adalah ketika air didalam tandon mulai berkurang, maka botol plastik akan turun kebawah dan tali yang terhubung antara botol plastik dan saklar akan saling tertarik dan mengakibatkan pengait besi tertarik dan mengubah saklar yang terhubung pompa air dari kondisi off menjadi on. Sedangkan saat air didalam tandon penuh botol plastik akan bergerak ke atas sebelum air tumpah, bagian kepala botol plastik akan terangkat ke atas karena tekanan air yag terus masuk dan mengakibatkan saklar yang terhubung pompa air berpindah dari kondisi on menjadi off. Setelah dilakukan uji coba alat berulang kali alat Water Level Control sederhana ini memiliki keakuratan dalam menentukan kapan pompa air harus menyala atau mati sehingga alat ini cukup efektif dan efisien dalam penghematan air dan listrik di kawasan perumahan. Namun dalam penelitian belum dilakukan pengujian terhadap daya tahan dari masing-masing bahan yang digunakan sehingga perlu dilakukan penelitian lanjutan dalam hal tersebut agar diketahui umur ekonomis dari alat tersebut.

\section{Daftar Pustaka}

Achmad, Andani dan Umraeni, A. Ejah. (2011). Penentuan Level Air Tangki dengan Sistem Kendali. Jurnal Ilmiah Elektrikal Enjiniring UNHAS, Vol. 9, No. 2, pp. 78-82.

Adini, G. D. (2012). Analisis Potensi Pemborosan Konsumsi Energi Listrik pada Gedung Kelas Fakultas Teknik Universitas Indonesia. Jakarta: Universitas Indonesia.

Anonim. (2013). " Pembangunan kota Solo, sejumlah investasi di kota Solo memunculkan Masalah air Bersih". Solopos, 18 januari 2016

Anonim. (2013). "150 KK Mulai Krisis Air Bersih". Sindo,06 Agustus 2016 
Arifin, Ilham. (2009). Automatic Water Level Control Berbasis Mikrocontroller Dengan Sensor Ultrasonik. Laporan Skripsi.Semarang : Universitas Negeri Semarang

Dewanto, Joni dkk. (2000). Pemodelan Sistem Pengatur Ketinggian Air pada Sebuah Tangki Tunggal. Jurnal Teknik Mesin, Vol. 2, No. 1, pp. 35-40.

Hariyanto, Dwi Pipit, dan Anto Cuswanto. (2010). Otomatisasi Pengisian Penampung Air Berbasis Mikrokontroller AT8535. Jurnal Ekonomi dan Pendidikan, Vol. 1, No. 1.

Haryanto (2007). Kendali Motor Pompa Berdasarkan Ketinggian Air Dengan Sensor Elektroda. Semarang: Haryanto.

Kuswandi , Rio. (2013). " Krisis Air Bersih di Kota Bandung, Jawa Barat". Kompas, 02 November 2015.

Nakhoda, Yusuf Ismail, Rizky Huda. (2009). Sistem Kontrol Level Ketinggian Air pada Tandon Menggunakan SMS Berbasis Smart Relay. Prosiding SENTIA, pp. 82-85.

Suroso, Dwi Priyantoro, dan Yordan Krisandy. (2012). Pembuatan dan Karakterisasi Pompa Hidrolik Pada Ketinggian Sumber 1,6 Meter. Seminar Nasional VIII SDM Teknologi Nuklir, pp. 271-276. (Yogyakarta, 31 Oktober 2012)

Suryaningtyas, Yoanitantia A. (2013). Rancangan Bangun Water Level Control Berbasis Mikrokontroler ATMEGA 8535. Semarang: Universitas Diponegoro.

Wahyudi, Bakhtiar Indra K, dan Iwan Setiawan. (2008). Perencanaan Sistem Pengendalian Debit Aliran Masukan Pada Tandon Air Dengan Menggunakan Mikrokontroler Atmega 8535. Prosiding Seminar Nasional Teknoin.

Widiastuti, Oktisa. (2014). Perancangan dan Implementasi Sistem Pengisian Air Berbasis Programmable Logic Control (PLC) Omron CPM2A. Semarang: Universitas Diponegoro. 